\title{
COMMUNICATION ABOUT A BUSINESS MODEL WITHIN AN ORGANISATION IN THE OPINION OF CZECHS AND POLISH
}

\author{
Marcin Komańda ${ }^{1}$ \\ ${ }^{1}$ University of Economics in Katowice, Poland, marcin.komanda@ue.katowice.pl
}

\begin{abstract}
Business models are nowadays a popular topic in management science. The concept of ontology of business models in particular is used in numerous scientific works within this scope. The issue of shared understanding of a business model within an organisation is becoming essential in this regard. Therefore, this work presents the opinions of young Czechs and Polish studying on faculties of management on the issue of the subject matter of a business model in the dimensions of the way it is communicated within an organisation. The study has been conducted with the aid of a survey. Hundred and twenty persons altogether have given their answers, of which $50 \%$ were Polish and the other $50 \%$ were Czechs. The existence of statistically important correlation between independent variables ('nationality', 'seniority') and opinions concerning particular dimensions of communicating about business models within an organisation (dependent variables) has been proven. The existence of these correlations (despite their very low level) in the light of a generally formulated research problem may constitute a premise for conducting further studies on the issue of cultural conditionings of communicating about this problem as well as the way it is practised in Polish and Czech enterprises.
\end{abstract}

Keywords: business; model; opinion; communication; organisation.

Type of the paper: Empirical study

JEL Classification: M10, M14.

\section{Introduction}

In recent years, the issues of business models have become one of the most popular subjects of publications within the scope of management sciences, which may be proven by two facts. First of all, the number of publications on this issue and secondly, the number of citings of these publications (Komańda 2014). The reasons for such popularity should be, above all, sought within the development of e-business that simultaneously induced the necessity for describing new forms of running a commercial activity and, as a result, made devising of a new method of their description possible. The use of IT infrastructure as a basis for the activity conducted by e-business enabled to adopt the concept of ontology in the description of these forms of business, and, based on it, the description of business models themselves (Osterwalder et al. 2005). Popularisation of methods based on the ontological approach (e.g. $\mathrm{e}^{3}$ value (Gordijn et al. 2006), BMO (Osterwalder 2004)) as a consequence resulted in devising tools of business model management in the form of IT programmes supporting managers of enterprises in the decision-making process.

The use of a ready tool for business model management or independent attempt to describe the model requires broad understanding of its essence within the enterprise itself, method for its description and, as a result, elements of this model. The research objective of the presented work is, therefore, to define the significance of the communication process for the purposes of setting up ontology of a business model of an enterprise. It should be emphasised that the role of this process has been referred to key aspects of a business model ontology. Simultaneously, whilst analysing the issues of communication process, one should also raise the issue of cultural differences influencing, amongst other things, its efficiency. Thus, the main research hypothesis $(\mathrm{H})$ is as follows: there is a correlation between nationality and the perception of necessity for communicating about the building components of a business model ontology within an enterprise.

In order to verify the hypothesis made, a research tool in the form of a survey had been devised, which was made available to the respondents from Czech and Poland. The respondents were students at 
management faculties. They were students of the Brno University of Technology (Czech) and the University of Economics in Katowice (Poland). Selecting such group of respondents was a deliberate procedure; however, it means that the results of the conducted analysis may only be referred to the surveyed group of respondents. The analysis of results of the research procedure enabled, above all, to determine that there is a statistically significant weak correlation between the necessity for communicating (in the opinion of respondents) about two key aspects of business model ontology of an enterprise (dependent variables) and the nationality of respondents (independent variable). Those distinguished aspects of creating a business model are conceptualisation of a business model as a bridge between a strategy and operational activity of an enterprise and presenting a business model as a machine scheme. Because of the age of the respondents who were only about to begin their professional activity or who had a relatively short seniority, the decision was made to broaden the analysis by this factor. It means that seniority was assumed as another independent variable. It enabled to establish a statistically significant and also weak correlation with the following dependent variables: accepted terminology and presenting of a business model as a machine scheme. The obtained results of the analysis enable to assume that it is worth conducting further, deepened and representative studies on cultural conditionings of communicating about business model ontology in the conditions of Polish and Czech enterprises.

\section{Literature Review}

Whilst referring to the issue of presenting the form of a business model, it should be emphasised that a conceptual category which it refers to whilst taking such measure should be established. As it is pointed out in the literature on the subject, one may avail oneself of one of the three possible categories of defining business models that are in hierarchical relations with one another (on higher levels metamodels are to be distinguished (Gordijn, Akkermans 2003) also known as reference models (Hamel 2001)). First of all, business models may be defined as concepts the description of which includes all their types existing in the economic reality. Second, one may focus on the description of various abstract features of business models (for this purpose, a particular classification is used); the consequence is a description of business models of particular features. And third, one may focus on matter-of-factly existing aspects (or their conceptualisation) of business models of particular enterprises (Osterwalder et al. 2005).

The cited authors point out that each of these approaches has its justification, each of them may turn out to be fruitful and may be useful in the description of business models. According to them, they may also be completed out of simple definitions or a more complex series of elements and establishing relations between them. The metamodel approach (i.e. their hierarchisation) uses the concepts of reference models characteristic for a given market and assumes an infinite number of business models characteristic for particular enterprises. From this point of view, models become a shared, formal and openly expressed conceptualisation. Simultaneously, expressing this conceptualisation undergoes further specifications that may lead to distinguishment of sub-metamodels on the road of further classifications (which use the similarity criterion) (Lambert 2006).

A characteristic phenomenon for the perspective of the issue of business models with respect to metamodels (reference models) is also the use of the notion of the business model ontology (George, Bock 2011). In this approach, ontology is based on a specific understanding of the following notions: conceptualisation connected with presenting 'the model' as business logic (also known as business logic triangle, which includes strategy, business model and business processes (Osterwalder, Pigneur 2004); conceptualisation divisibility/universality, which is created on the basis of ontological liability (common interpretation of the business model by the interested parties that is built on the basis of the accepted terminology); technicality, that is presenting a business model as a "machine scheme"; openness understood not only as a way in which people understand this model but also as documentation by which it is described (Gordijn et al. 2005). Creating a business model ontology in the above-mentioned dimensions is definitely connected with the process of communication that includes, inter alia, communication with employees of an enterprise, creating an organisational database and knowledge and communicating in the conditions of emergency and implementation of changes (Cornelissen 2014). As a consequence, one should also refer to the issue of prospective 
cultural differences in the dimension of international comparisons of this very problem (Moran et al. 2014).

From this perspective, a business model ontology is a rigidly established conceptual framework that enables to divide a common comprehension of what is significant (what expresses the essence, or the gist) and should be communicated amongst people and realised within sub-systems of an enterprise, especially in the context of actually realised processes (Aguilar-Saven 2004). The ontology, therefore, brings into use 'a general view/theory' (reference model) instead of a particular, specific and developed structure of elements that create the whole, which, as it is often emphasised, is not even fully known to managers of an enterprise (Fensel et al. 2001). The confirmation of this observation may also be found in other theses that state that a business model is not a description of a complicated social system, that is, an enterprise, which includes all its actors, relations and processes. A business model from this perspective is treated as a conceptual and architectural (i.e. in accordance with the assumed ontological assumptions) implementation of a strategy that becomes a foundation for the implementation of business processes (Petrovic et al. 2001). What is more, nowadays, business models are perceived as a holistic way of analysing the activity of enterprises without the necessity to refer to the existing set of clients, cooperators and competitors. Therefore, they are a consequence of presentation of a key idea for running a business as a peculiar idea prescinding from the real situational context (thus, in this respect, they constitute a metamodel). It contributes to the possibility of broadmindedness of key decision-makers regarding innovativeness within a business model of an enterprise, first, in a general manner, the consequences of which are improvements of particular aspects of running a business in a practical dimension (Amit, Zott 2012), that is on the level of a given enterprise.

\section{Methodology}

The conducted intent of the research was assumedly of explorative nature and concerned the issue of cultural differences in the context of opinions regarding the necessity for communicating about business model ontology within an enterprise. The choice of Polish and Czech nationalities for the purposes of the research is justified by significant cultural differences that exist between them and that are described in the results of studies on cultural differences published on Hofstede Center's website. The very fact of these cultural differences exists, despite the affiliation of both nationalities to the group of Slavic nations and their direct geographical proximity in the region of Central and Eastern Europe.

The selection of respondents with regard to the nature of the research was deliberate and consisted in selecting students of management departments for the participation in the research (non-probability sampling method, convenience sample). This selection of respondents arose from, above all, a general nature of the question posed in the used research tool, which took the form of a survey questionnaire. Thus, it enabled to receive a response from a homogeneous group of people in terms of the direction of studies who might have understood research intentions and intuitively responded to the questions they were shown. Another factor in the selection of such a group of respondents was an ease-reaching.

Table 1. Distribution of respondents according to their nationality and level of studies (Source: author's compilation)

\begin{tabular}{|c|c|c|c|}
\hline \multirow{2}{*}{ Current level of studies } & \multicolumn{2}{|c|}{ Nationality } & \multirow{2}{*}{ Total } \\
\hline & Czechs & Poles & \\
\hline Bachelor & 30 & 32 & 62 \\
\hline Master & 29 & 28 & 57 \\
\hline Doctoral & 1 & 0 & 1 \\
\hline Total & 60 & 60 & 120 \\
\hline
\end{tabular}


Altogether 120 persons responded. Half of them were students of the Faculty of Management at the University of Economics in Katowice (Poland), the other half were students of the Faculty of Management at the Brno University of Technology (Czech). The number of respondents on the account of nationality and current level of studies is shown in Table 1.

Owing to the fact that amongst the respondents were young persons beginning their professional life or being about to take up their first employment, they were asked to assess their seniority taking into account all prospective forms of employment. Table 2 shows distribution of respondents on account of nationality, level of studies and seniority.

Table 2. Distribution of respondents by nationality, level of studies and seniority (Source: author's compilation)

\begin{tabular}{|c|c|c|c|c|c|c|}
\hline \multicolumn{6}{|c|}{ Seniority } & \multirow{3}{*}{\begin{tabular}{|c|} 
Total \\
30 \\
\end{tabular}} \\
\hline \multicolumn{3}{|c|}{ Nationality/Level of studies } & Never & Worked not & & \\
\hline \multirow{4}{*}{ Czechs } & \multirow{3}{*}{$\begin{array}{l}\text { Current } \\
\text { level of } \\
\text { studies }\end{array}$} & Bachelor & 15 & 6 & 9 & \\
\hline & & Master & 8 & 9 & 12 & 29 \\
\hline & & Doctoral & 0 & 0 & 1 & 1 \\
\hline & \multicolumn{2}{|c|}{ Total } & 23 & 15 & 22 & 60 \\
\hline \multirow{3}{*}{ Poles } & \multirow{2}{*}{$\begin{array}{l}\text { Current } \\
\text { level of } \\
\text { studies }\end{array}$} & Bachelor & 7 & 10 & 15 & 32 \\
\hline & & Master & 3 & 4 & 21 & 28 \\
\hline & \multicolumn{2}{|c|}{ Total } & 10 & 14 & 36 & 60 \\
\hline \multirow{4}{*}{ Total } & \multirow{3}{*}{$\begin{array}{l}\text { Current } \\
\text { level of } \\
\text { studies }\end{array}$} & Bachelor & 22 & 16 & 24 & 62 \\
\hline & & Master & 11 & 13 & 33 & 57 \\
\hline & & Doctoral & 0 & 0 & 1 & 1 \\
\hline & \multicolumn{2}{|c|}{ Total } & 33 & 29 & 58 & 120 \\
\hline
\end{tabular}

The verification of the stated hypothesis $(\mathrm{H})$ required writing it in the form of detailed hypotheses. Their formula was taken from key component issues regarding understanding of a business model ontology of an enterprise (Gordijn et al. 2005). Therefore, the consecutive hypotheses are as follows:

H1: There is a correlation between nationality and opinion about the necessity for communicating about a business model as conceptualisation of a bridge between a strategy of an enterprise and operational level.

$\mathrm{H} 2$ : There is a correlation between nationality and opinion about the necessity for creating a commonly accepted terminology describing a business model by the communication process within an enterprise.

$\mathrm{H} 3$ : There is a correlation between nationality and opinion about the necessity for propagating the image of a business model as a machine scheme by the communication process.

H4: There is a correlation between nationality and opinion regarding the necessity for creating and propagating within an enterprise documentation describing a business model by the communication process.

One question corresponded to each of the hypotheses. The respondents were supposed to reply by choosing the value from 1 to 5 , where the lowest value in the opinion of a respondent meant absolute lack of necessity of a chosen aspect of the communication process for creating a business model ontology within an enterprise, whereas the highest value reflected the opposite attitude, that is, the opinion about absolute necessity. Owing to the fact that ordinal variables (respondents' opinions) and nominal variables (nationality) were used, Goodman and Kruskal's tau measure of correlation was used for the verification of the hypotheses (Górniak, Wachnicki 2013). Calculations were made with the aid of the statistical programme PS Imago. 


\section{Results}

The respondents were asked whether particular aspects of understanding of a business model as a conceptual framework for the description of the essence of the conducted activity should constitute the subject of communicating within an enterprise. In response to the question regarding the necessity for communicating about a business model as a conceptualisation of the bridge between a strategy of an enterprise and level of realisation of processes, the main differences in distributions of respondents' indications because of their nationality concern three options of answers. The answer option 'I have no opinion' was chosen by 29 persons in case of Poles ( 7 persons amongst Czechs). The answer option 'I rather agree' was chosen by 30 Czechs and 22 Poles. Whilst, the answer option 'I agree' was marked by 14 Czechs and 1 Pole. The response determinant on the side of the indications of Poles was 'I have no opinion' (29 indications), and in case of Czechs, 'I rather agree' (30 indications). In case of both nationalities, one may also point out the existence of two 'I don't agree' answers, respectively. The answers of the respondents are presented in the Fig. 1,

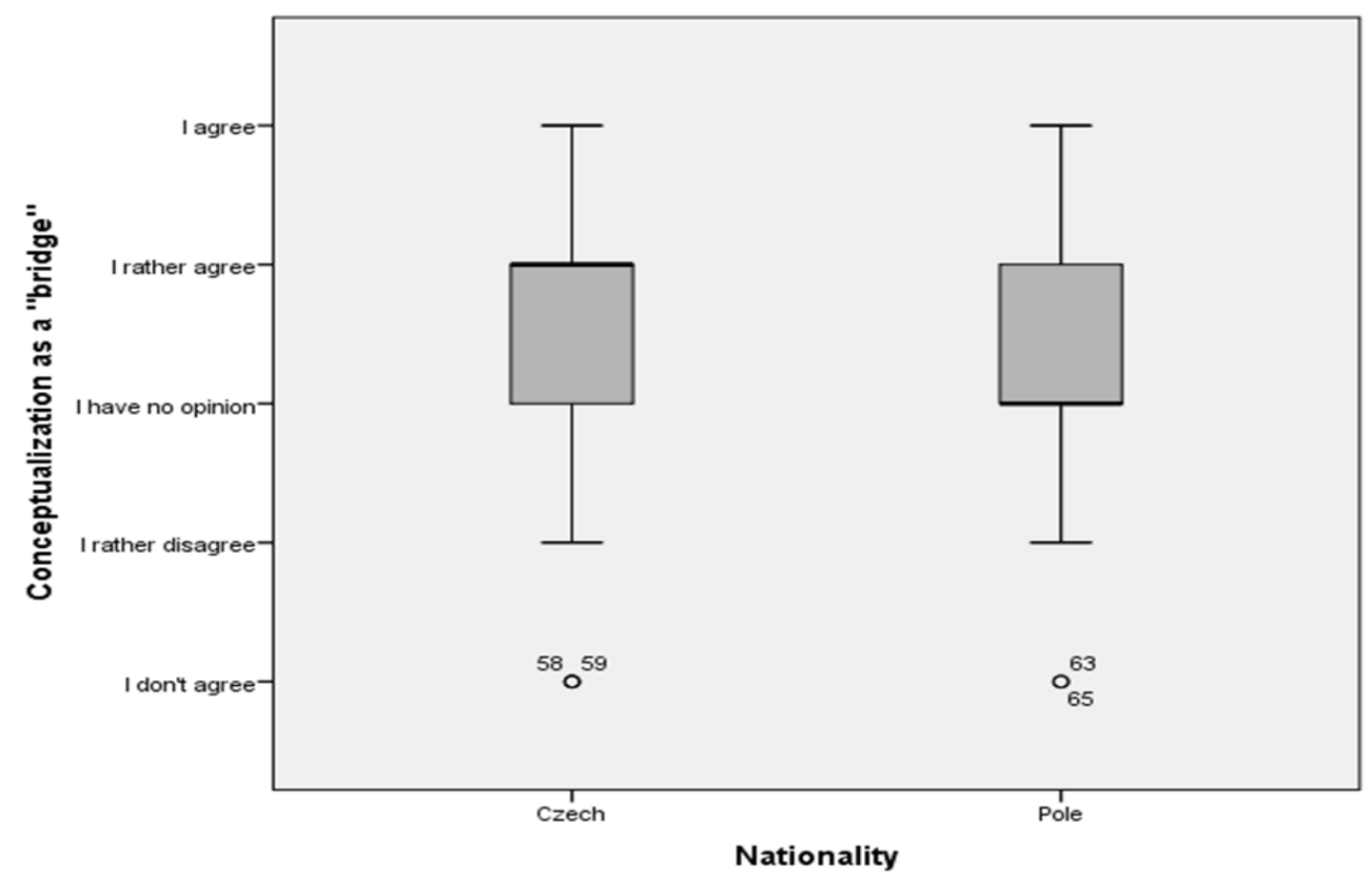

Fig. 1. Distribution of answers for variables 'conceptualisation as a bridge' and 'nationality' (Source: author's compilation generated by PS Imago)

Distribution of responses to the question regarding the necessity for creating by the communication process within an enterprise-accepted terminology describing a business model indicates that the most popular answer option amongst respondents was 'I rather agree': 53 indications altogether ( 23 Czechs and 30 Poles). These are simultaneously the dominants in both groups of respondents. In case of indications of persons of the Czech, nationality responses concentrated on three middle answer options ('I rather disagree', 'I have no opinion', 'I rather agree' - 53 indications altogether). In turn, Poles chose the answer options 'I rather agree', 'I agree, and 'I have no opinion' 53 times altogether. The answers of the respondents are presented in the Fig. 2. 


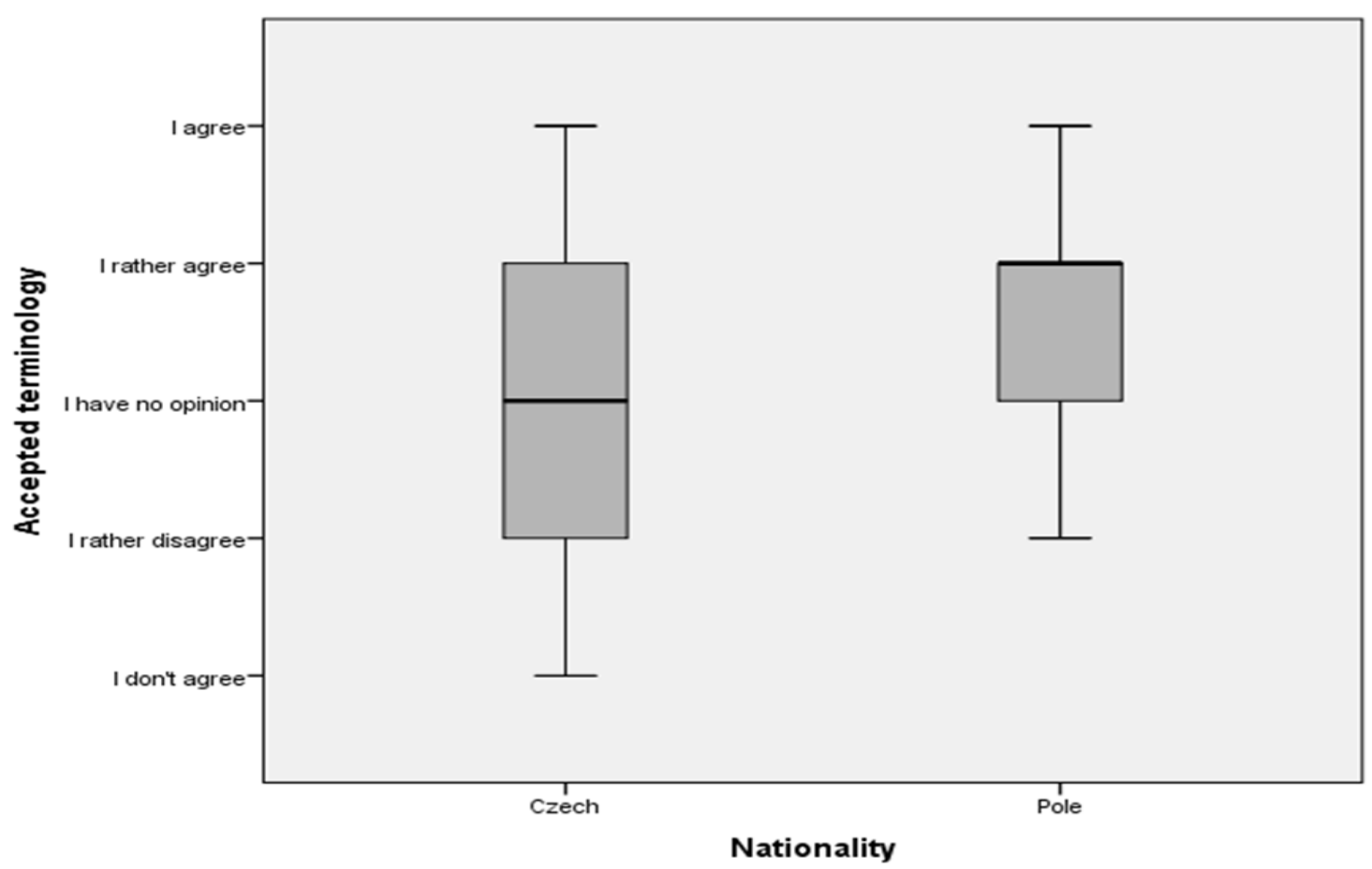

Fig. 2. Distribution of answers for variables 'accepted terminology' and 'nationality' (Source: author's compilation generated by PS Imago)

In case of the expressed opinions about the necessity for propagating by the communication process, the image of a business model as a machine scheme Poles more often than Czechs chose the following answer options: 'I agree' (15 indications) and 'I rather agree' (29 indications - the dominant). Czechs gave 11 and 18 indications to these questions, respectively. In their case, the dominant was the answer option 'I have no opinion'. This answer option was indicated by 20 Czechs (see Fig. 3).

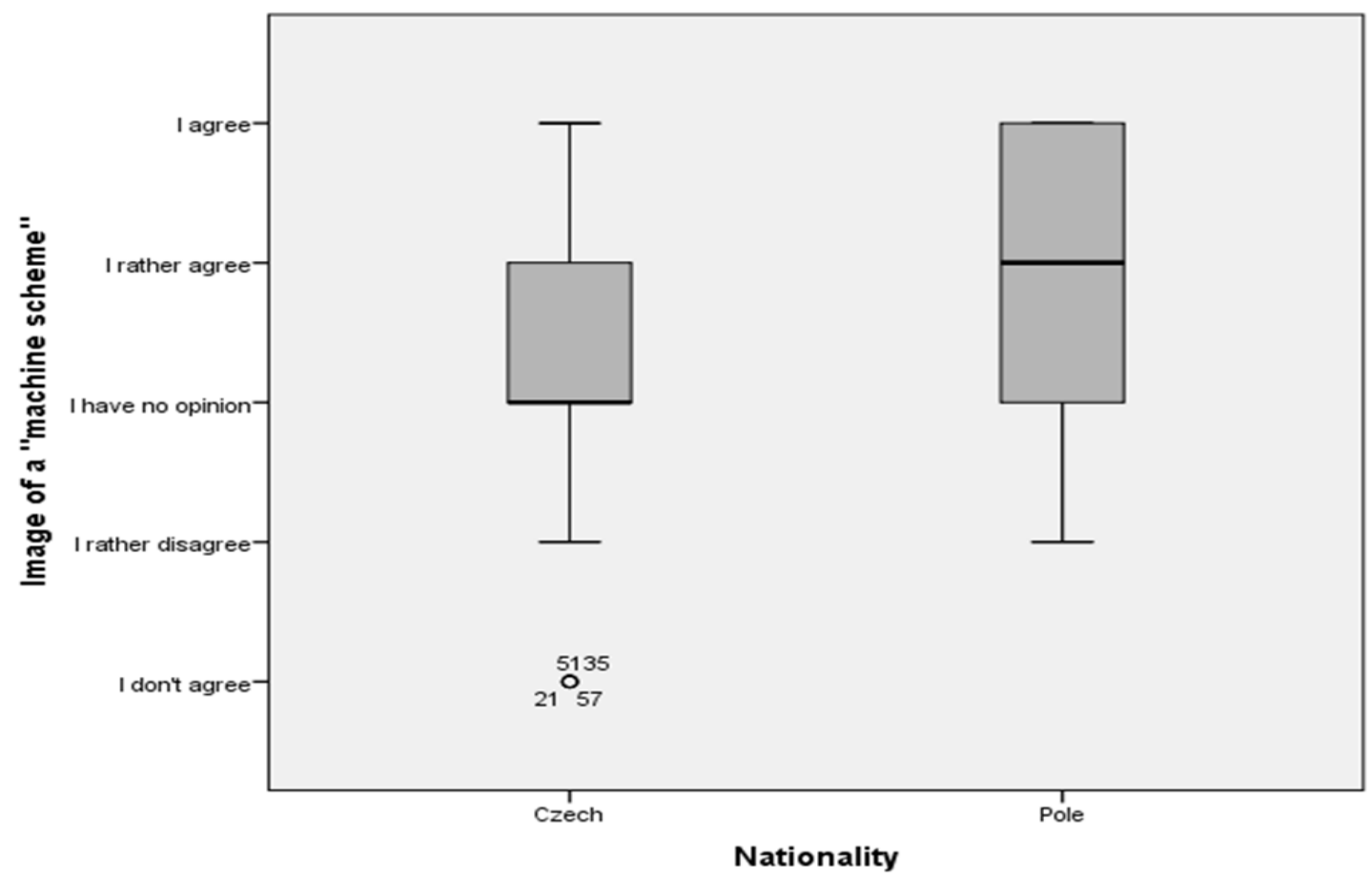

Fig. 3. Distribution of answers for variables 'image of a machine scheme' and 'nationality' (Source: author's compilation generated by PS Imago) 
The opinions expressed in the last question that concerned the necessity for creating and disseminating of documentation describing a business model of an enterprise by the communication process in both groups of respondents were almost identical. Prospective differences in the distribution of answers between groups of respondents amount to two indications maximally. The dominant in both groups of respondents was the answer option 'I rather agree'. Poles indicated it 23 times, whereas Czechs 24 times (see Fig. 4).

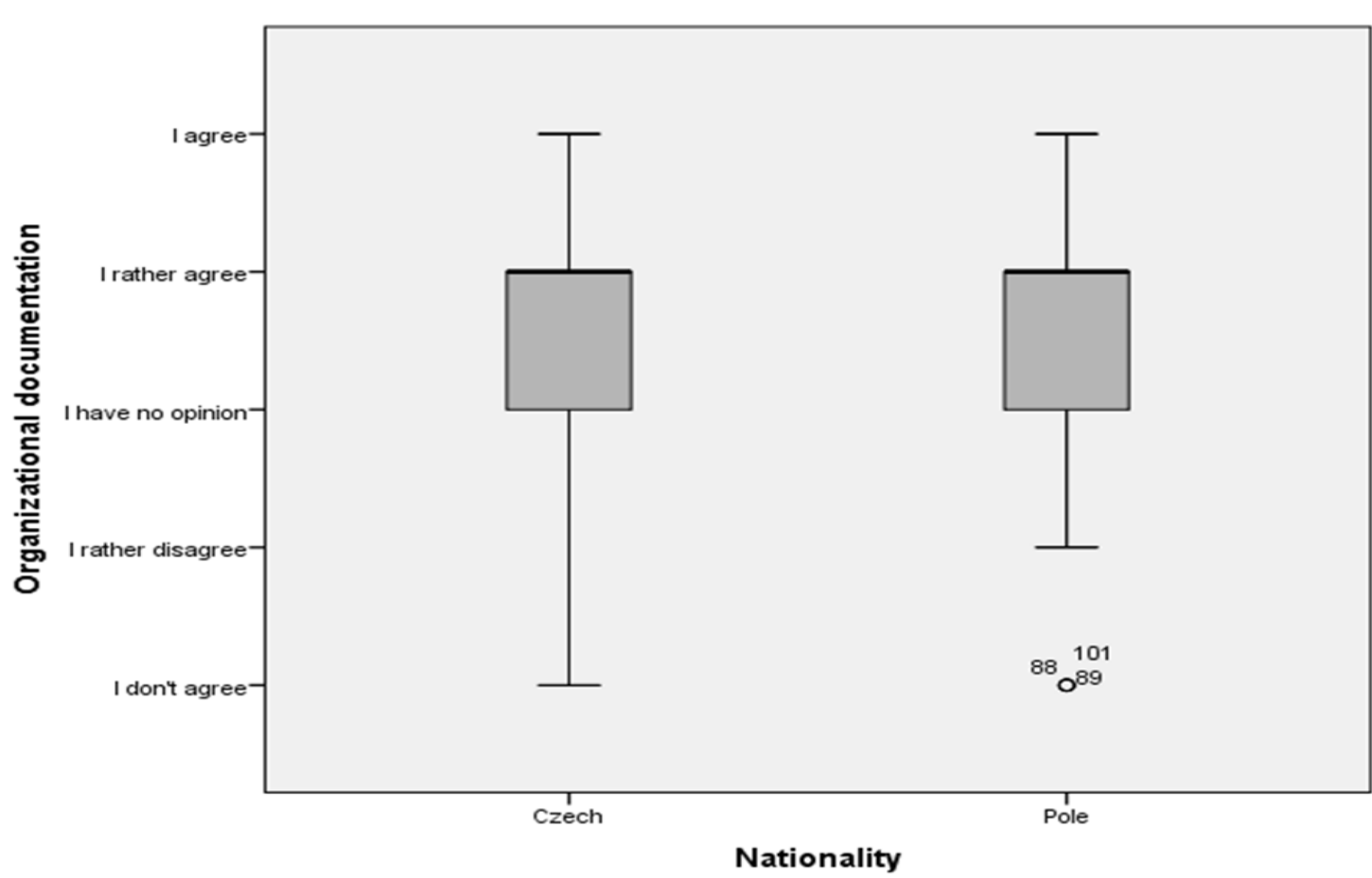

Fig. 4. Distribution of answers for variables 'organisational documentation' and 'nationality' (Source: author's compilation generated by PS Imago)

On the basis of the presented distribution of responses, Goodman and Kruskal tau correlation coefficient has been calculated between the independent variable 'nationality' and four dependent variables for which the distribution of responses has been shown. The results have been presented in Table 3 .

Table 3. Goodman and Kruskal tau correlation coefficient between independent variable 'nationality' and dependent variables (Source: author's compilation generated by PS Imago)

\begin{tabular}{|l|c|c|c|c|}
\hline \multicolumn{1}{|c|}{ Dependent variable } & Value & Significance* & Hypothesis & Status \\
\hline Conceptualisation as a bridge & .072 & .000 & H1 & Accepted \\
\hline Accapted terminology & .016 & .110 & H2 & Rejected \\
\hline Image of a machine scheme & .021 & .039 & H3 & Accepted \\
\hline Organisational documentation & .001 & .992 & H4 & Rejected \\
\hline
\end{tabular}

* Based on approximation of chi-square distribution.

Goodman and Kruskal tau correlation coefficient is in the range $<0 ; 1>$. It means that in two cases, a weak but statistically significant relationship between variables has been indicated. The assumed hypotheses were, therefore, confirmed for these cases (Table 3).

The analysis was completed by the prospective study on the existence of correlation between independent variable 'seniority' and four dependent variables being discussed. Unfortunately, as results from Table 2, there is over-representativeness of a group of persons who 'never worked' in case of Czechs in relation to Poles, and in case of Poles in relation to Czechs, there is over- 
representativeness of 'worked at least 1 year' group. Therefore, it was decided that the analysis of existence of consentience of respondents' opinions regarding particular should be made concomitantly for both groups of respondents and that the results of the analysis should be treated in a supplementary way for the discussions presented in this work.

Table 4. Goodman and Kruskal tau correlation coefficient between independent variable 'seniority' and dependent variables (Source: author's compilation generated by PS Imago)

\begin{tabular}{|l|c|c|}
\hline \multicolumn{1}{|c|}{ Dependent variable } & Value & Significance* $^{*}$ \\
\hline Conceptualisation as a bridge & .019 & .324 \\
\hline Accapted terminology & .035 & .034 \\
\hline Image of a machine scheme & .036 & .028 \\
\hline Organisational documentation & .019 & .336 \\
\hline
\end{tabular}

* Based on approximation of chi-square distribution.

In this case, the existence of a statistically significant correlation for two dependent variables with an independent variable, namely, seniority, could have been confirmed. Again, the variable 'image of a machine scheme' as well as the variable 'accepted terminology' appeared amongst them. In both the cases, the strength of the relation is also weak. In case of the first statistically significant correlation (for the variable 'accepted terminology'), 56 persons altogether amongst respondents of indicated seniority, which constituted $46.67 \%$ of all the respondents, rather agreed or agreed with the issue. The indicated correlation for the second variable ('image of a machine scheme') in the opinion of respondents who possess work experience achieved a similar level of acceptance. In case of answer options 'I agree' or 'I rather agree', the number of responses amounted to 54, which constituted $45 \%$ of all indications.

\section{Conclusions}

The results of studies concerning national cultures based on G. Hofstede's method (value for six dimensions of culture) point out that Poles in the cultural sphere are characterised by fundamental ambivalence. On the one hand, they accept hierarchical relations, have emotional need for the existence of values and are not open to non-standard actions and way of thinking. On the other hand, however, Poles are a society of individualists who have a tendency to be cynics, pessimists and who think that social norms limit them. It is emphasised that this ambivalence in the features of national cultures makes relations built with Poles often very fragile, but if they are built and sustained in an appropriate manner, they may turn out to be very fruitful (The Hofstede Centre 2010b). Czechs, on the other hand, treat a particular social hierarchy, including the one within an organisation, as a natural thing. They expect to be informed about what they are supposed to do, and in their opinion, a supervisor should be a friendly authoritarian. Employer-employee relationships are based on mutual benefits, whereas decisions regarding employment or professional promotion should be connected with merits. Managers should be firm and determined, treat their subordinates equally and manage them in an individual manner, whereas work is aimed at the results achieved. Czechs have also an emotional need for rules. The key difference between Poles and Czechs, however, lies in the dimension referred to as 'long-term orientation'. Czechs are, therefore, in this dimension described as a pragmatic society, which means that they think that the truth depends on the context of place and time. They are prone to adapting traditions to contemporary conditionings or manifest a tendency to save and invest. Poles, in turn, are a normative society that attempts to function in the conditions of the so-called absolute truth. They respect tradition, have a low tendency to save and think about the future. They are orientated towards achieving short-term goals (The Hofstede Centre 2010a).

The first accepted hypothesis concerned the existence of a correlation between nationality and opinion about the necessity for communicating about a business model as a conceptualisation of a bridge between a strategy of an enterprise and operational level. Whilst analysing the distribution of responses, it may be stated that in both groups of respondents, the opinions were convergent; however, they differed within the scope of the value of dominants. In case of the researched opinions within the group of Czechs, there was a greater acceptance of this issue. If the assumption is made that 
conceptualisation of a business model as a bridge connecting a strategy of an enterprise with operational level is related to bringing the sense to what is being done within an enterprise, it may be stated that from the perspective of the need for order, rules and orientation towards achieving goals a greater acceptance on the side of Czechs as well as general acceptance in both groups of respondents should not come as a surprise.

The second accepted hypothesis concerned the existence of a correlation between nationality and opinion about the necessity for propagating the image of a business model as a machine scheme by the communication process. In this case, the distribution of responses shows that there was a greater acceptance of this issue in the opinion of respondents expressed by Poles who participated in the study. It may seem rather surprising because, according to studies, Czechs manifest a tendency to appreciate a systematic and structured approach (Wursten, Fadrhonc 2012). On the other hand, such result may also signify that on the side of Poles, there was a strong expression of the necessity for the existence of rules and standard action. As a result of generally worded questions of the study, it is currently impossible to determine what the reason for the result achieved was.

However, it indicates a possibility to conduct further deepened studies within this scope. Winning a representative sample of respondents as well as using a structure of questions expressing cultural differences, especially within the scope of a relation towards hierarchical relationships, standards of action and motivational factors may contribute to revealing of stronger relations between nationality (Czechs/Poles) and opinion regarding creating of a business model ontology by the communication process within an enterprise.

Another interesting thing is, though only slightly outlined in the work, the issue of the existence of a correlation between components of creating a business model by the communication process within an enterprise and seniority of studied respondents. In this case, it is worth mentioning that a statistically significant correlation between seniority and necessity for creating a commonly accepted terminology describing a business model of an enterprise. From the perspective of experience gained in the course of the realisation of scientific projects within the scope of business models, the author of this work may confirm that one of the main issues he would come across within enterprises was lack of shared understanding of key aspects indispensable for the description of this model within an organisation as well as linguistic terms that describe it. Prospective confirmation of the obtained result in further studies could point out that members of an organisation themselves as well, along with professional development, begin to notice such problem.

\section{Acknowledgements}

Support for this work was provided by the Faculty of Business and Management, Brno University of Technology, the host of author's scientific internship in 2015.

\section{References}

Aguilar-Saven, R. S. (2004). Business Process Modelling: Review and Framework. International Journal of Production Economics, (2), 129-149.

Amit, R., \& Zott, C. (2012). Creating Value Through Business Model Innovation. MIT Sloan Management Review, (3), 41-49.

Cornelissen, J. (2014). Corporate Communication: a Guide to Theory and Practice. Sage Publications. Ltd..

Fensel, D., McGuiness, D., Ng, W. K., \& Yan, G. (2001). Ontologies and Electronic Commerce. Intelligent Systems, IEEE, (1), 8-14.

George, G., \& Bock, A. J. (2011). The Business Model in Practice and Its Implications for Entrepreneurship Research. Entrepreneurship Theory and Practice, (1), 83-111.

Gordijn, J., \& Akkermans, J. (2003). Value-based Requirements Engineering: Exploring Innovative e-Commerce Ideas. Requirements Engineering, (2), 114-134. 
Gordijn, J., Osterwalder, A., \& Pigneur, Y. (2005). Comparing Two Business Model Ontologies for Designing eBusiness Models and Value Constellations. In $18^{\text {th }}$ Bled eConference: elntegration in Action. Conference proceedings. [Accessed 06.01.2016]. Available from Internet: http://aisel.aisnet.org/bled2005/15

Gordijn, J., Yu, E., \& van der Raadt, B. (2006). e-Service Design Using i* and e3value Modeling. IEEE Software, (3), 26-33.

Górniak, J., \& Wachnicki, J. (2013). Pierwsze kroki w analizie danych. IBM SPSS Statistics. Kraków: Predictive Solutions.

Hamel, G. (2001). Leading the Revolution: an Interview with Gary Hamel. Strategy \& Leadership, (1), 4-10.

Komańda, M. (2014). Methodology of Creating Business Models in the Educational Effects within the Scope of Knowledge at the Management Major: the Case of the Bachelor's Degree at the University of Economics in Katowice. International Journal of Arts \& Sciences, (6), 313-323.

Lambert, S. (2006). Do We Need a 'Real' Taxonomy of e-Business Models?. School of Commerce Research Papers Series, (6), 1-11.

Moran, R. T., Abramson, N. R., \& Moran, S. V. (2014). Managing Cultural Differences. London and New York: Routledge, Taylor \& Francis Group.

Osterwalder, A. (2004). The Business Model Ontology. A Proposition in Design a Science Approach. Docteur en Informatique de Gestion, Lausanne: Universite de Lausanne. [Accessed 15.12.2015]. Available from Internet: http://www.uniempre.org.br/user-files/files/TheBusiness-Model-Ontology.pdf

Osterwalder, A., \& Pigneur, Y. (2004). An Ontology for e-Business Models. In Value Creation from e-Business Models. W.L. Currie (Editor). Burlington: Elsevier Butterworth Heinemann.

Osterwalder, A., Pigneur, Y., \& Tucci, C. L. (2005). Clarifying Business Models: Origins, Present, and Future of the Concept. Communications of the Association for Information Systems, (1), 1-25.

Petrovic, O., Kittl, C., \& Teksten, R. D. (2001). Developing Business Models for eBusiness. [Accessed 11.11.2015]. Available from Internet: http://papers.ssrn.com/sol3/papers.cfm?abstract_id=1658505

The Hofstede Centre (2010a). What about Czech Republic?[Accessed 09.10.2015]. Available from Internet: https://geert-hofstede.com/czech-republic.html

The Hofstede Centre (2010b). What about Poland?[Accessed 09.10.2015]. Available from Internet: http://geerthofstede.com/poland.html

Wursten, H., \& Fadrhonc, T. (2012). International Marketing and Culture. [Accessed 07.12.2015]. Available from Internet: http://geert-hofstede.com/tl_files/Marketing_and_Culture_itim_International.pdf 